\title{
EXPERIMENTAL INVESTIGATION ON THE PERFORMANCE AND EMISSION CHARACTERISTICS OF COMPRESSION IGNITION ENGINE FUELLED WITH VARIOUS BLENDS OF WATER MELON BIODIESEL
}

\author{
R. RAJASEKAR ${ }^{1}$ \& Dr. P. NAVEENCHANDRAN ${ }^{2}$ \\ ${ }^{1}$ Research Scholar, Department of Automobile Engineering, BIHER, Chennai, Tamilnadu, India \\ ${ }^{2}$ Professor \& Head, Department of Automobile Engineering, BIHER, Chennai, Tamilnadu, India
}

\begin{abstract}
The water melon biodiesel blends were tested in diesel engine without any modification blends reveals the better performance and emissions were observed. Five set of water melon biodiesel blend samples are prepared such as B20, B40, B60, B80 and B100. Properties of water melon blends are find out as per standards and compared to diesel fuel. Testing is carried out to analyze the performance and emission characteristics of diesel engine fuelled with various blends of Water melon biodiesel. The observation of testing fuels are conducted on kirloskar single cylinder water cooled constant speed direct injection diesel engine with eddy current dynamometer. The engine parameter such as injection timing $23^{\circ}$ bTDC and injection pressure 210 bars were maintained constant throughout the experiment. From the test results, it might be observed that among different blends B20 blend showed optimum performance and emission results compared with the neat diesel.
\end{abstract}

KEYWORDS: Biodiesel, Blends, Emission, Engine \& Transesterification

Received: Jun 02, 2020; Accepted: Jun 22, 2020; Published: Jun 30, 2020; Paper Id.: IJMPERDJUN2020259

\section{INTRODUCTION}

The energy necessities are escalating rapidly worldwide. Particularly fuel crisis is one of the biggest problems that have triggered interest to search for alternative fuels from bio-origin like vegetable based edible and non-edible oils. Growth of automobile vehicles in recent years created a greater demand for fossil fuels. Various investigators have carried out research work on the performance and emission of compression ignition engines using vegetable based biofuels as an alternative fuel owing to potential properties of the bio fuel $[1,2]$. Vegetable oil does not have sulphur, aromatic hydrocarbons and metals. Based on the weather and soil environment, researchers are seeking suitable bio fuels as a substitute for standard diesel fuels [3]. Vegetable oils cannot straightaway be chosen as a fuel in CI engines because of superior viscosity. High viscosity oil would obstruct the fuel passages which may lead to incomplete combustion, engine deposits in addition to contamination of lubricants. This can be overcome by employing various methods, such as pyrolysis, dilution, emulsification and Transesterification. Vegetable oils are triglycerides of long chain fatty acids which comprise triglycerides with small amounts of mono and di glycerides. Bio fuel is long chain unsaturated fat that could be chosen as a substitute fuel in pressure start motor. Thickness of hazelnut oil is just about multiple times more than that of standard diesel and hazelnut oil has $27 \%$ lower warming an incentive than standard diesel [4]. Different scientists have done research on the CI motor utilizing both consumable andnon-eatable oils, for example, squander cooking oils, rapeseed, soybean, palm, cotton seed, sesame, sunflower, elastic seed oil, mahua, Pongamia and jatropha [5,6].GauravDwivedi et al [7] investigated the effect of 
biodiesel on motor execution. The Indian economy is relied upon to develop and vitality request to ascend to 166 MT (Million Huge amounts of) of unrefined petroleum by 2019 and 622 MT by 2047. Ahmad et al [8] contemplated the attractiveness of bio fuel in the fuel segment for what's to come. Pongamia seeds yield 35\% oil by weight. Properties were diverging from biodiesel principles of ASTM.

JinlinXue et al [9] contemplated the aftereffect of bio fuel brake force, heartiness and fumes emanation also, detailed that bio fuel removed from sustainable sources would give the vitality necessities for transportation. Siddalingappa R. Hotti and Omprakash D. Hebbal [10] learned about the creation and portrayal of bio fuel from sugar apple oil what's more, detailed that the bio fuel yield was $95 \%$ at the ideal procedure conditions. Biodiesel properties were near the standard diesel and as per ASTM standard. Asokan et al [11] examined the qualities of pressure start motor worked utilizing diesel with papaya and watermelon bio fuel mixes. Execution of the motor fuelled with B20 was exceptionally near that worked with diesel. B20 is the most appropriate mix which reduces the diesel use by $15-20 \%$.

Yüksek et al [12] examined to locate the ideal pressure proportion in perspective on the rubbing misfortune and warm proficiency of the motor. Present day discharge control strategies are being utilized to CI motors to accomplish the low fuel utilization. Frictional vitality misfortune is turning into an indispensable factor for expanding the eco-friendliness. Pressure proportion which is a main consideration expands the chamber pressure and applies load on the motor segments. Shown force and erosion power expanded directly with expanding the pressure proportion.

Mathur et al [13] streamlined the estimation of pressure proportion of a variable Compression proportion pressure start motor. The most noteworthy brake warm effectiveness, least smoke limit and CO discharges were acquired with the pressure proportion of 17 and it was considered as the ideal pressure proportion for the CI motor. Khandal et al [14] showed discharges of a four stroke, regular rail infusion framework (CRDI) motor worked with honge biodiesel by differing the infusion timing, infusion weight and fumes gas re dissemination. The examinations were led according to full factorial structure. Numerical models dependent on reaction surface philosophy were utilized to discover the connection among the parameterswhat's more, its qualities. Hirkude and Padalkar [15] explored of the effect of compression ratio on the engine fueled with fried biofuel blend. It was noticed that a higher compression ratio enhances the engine thermal efficiency and reduces BSFC.The results inferred that $\mathrm{CO}$ and particulate matter emission declined whereas NOx emission increased with compression ratio.

\section{MATERIALS AND METHODS}

Oil is removed from the watermelon seeds utilizing expeller machine and is preheated to 60.C for around 60 minutes. About $25 \%$ of methyl liquor is taken and 0.6 gms of $\mathrm{NaOH}$ are broken down in it [19, 20]. Presently this arrangement is blended in with $1000 \mathrm{ml}$ of oil and mixed utilizing attractive stirrer at 60.C for 30 minutes. The methyl ester is isolated in isolating jar and water washed. The fuel properties like, Calorific Value and density have been determined by the indigenous set up as shown in table 1

Table1: Properties of Water Melon Biodiesel Blends

\begin{tabular}{|l|c|c|}
\hline \multicolumn{1}{|c|}{ Fuel } & Calorific Value (kJ/kg) & Density, $\mathbf{( K g / m 3 )}$ \\
\hline Diesel (B0) & 42800 & 842.8 \\
\hline B20 & 41140.434 & 855.44 \\
\hline B40 & 39480.868 & 868.08 \\
\hline B60 & 37821.302 & 880.72 \\
\hline B80 & 36161.736 & 893.36 \\
\hline
\end{tabular}




\begin{tabular}{|l|l|l|}
\hline B100 & 34502.17 & 906 \\
\hline
\end{tabular}

\subsection{Methodology}

The seeds were dried at room temperature, matured and ground in an electric blender. The examples of seeds (100g) and portions (100g) were extricated with oil ether (Merck, 40-600c) utilizing Sox let mechanical assembly for $6 \mathrm{hr}$ and the Extracted seed oil and Diesel blending proportion has been appeared in the below table.

\subsection{Transesterification Reaction}

It is most usually utilized and significant strategy to diminish the thickness of vegetable oils. Right now responds with three atoms of liquor within the sight of an impetus delivering a blend of unsaturated fats, alkyl ester and glycerol. The procedure of expulsion of all the glycerol and the unsaturated fats from the vegetable oil within the sight of an impetus is called esterification [16,17]. The Figure 2 shows the Transesterification procedure wherein the upper layer frames the ester and lower layer shapes the glycerol. The parameter, for example, temperature, molar proportion and impetus fixation that influence the Transesterification of Water melon oil were upgraded at first. The Transesterification set up houses $2 \mathrm{~L}$ Capacity, round base carafe furnished with three necks that was set in a water compartment for warming the oil. A warmer with a temperature controller was set in the round base cup. A fast engine with an attractive stirrer was utilized for fiery blending of the oil. In the Transesterification procedure triglycerides of Water melonoil responds with methyl liquor within the sight of impetus $(\mathrm{NaOH})$ to create an unsaturated fat ester and glycerol. Right now $\mathrm{g}$ Water melon oil, $230 \mathrm{~g}$ methanol and $8 \mathrm{~g}$ sodium hydroxide pellets were set in the round base carafe. The substance were warmed to $70^{\circ} \mathrm{C}$ and blended vivaciously for one hour to advance ester arrangement. The blend was next moved to an isolating channel and permitted to settle under gravity medium-term. The upper layer in the isolating pipe comprises of ester whist the lower layer is glycerol which was evacuated.The isolated ester with $250 \mathrm{~g}$ high temp water and permitted to settle under gravity for 24 hours. Water washing isolates lingering unsaturated fats and impetus and these were evacuated utilizing an isolating pipe. At long last the dampness from the ester was expelled by including silica gel precious stones. Different biodiesel-diesel mixes (B20, B40, B60, B80 and B100) were set up for the exploratory work.

\subsection{Experimental Setup}

A solitary chamber, direct infusion, four-stroke, water-cooled, Compression Ignition (CI) motor is utilized in the trial study. The specialized particular of the motor is given in Table2.The fuel stream rate was estimated by taking note of down the time taken for the utilization of a known amount of fuel $(10 \mathrm{cc})$ from a burette. The consistency of crude just as esterified oil was estimated by red wood Viscometer, thickness by hydrometer, calorific incentive by bomb calorimeter, glimmer and fire point by open cup technique. AVL-444 DI Gas analyzer was utilized to record the fumes tail pipe emanations, for example, $\mathrm{HC}, \mathrm{CO}$, and NOx. At first, before beginning exploratory tests, the motor was made to run under perfect condition as warm up stage and afterward the tests were directed. The motor was turned over and permitted to get ready for around 10 minutes. The motor was tried under five discrete part load conditions for example 20\%, 40\%, 60\%, $80 \%$ and $100 \%$. 


\section{RESULTS AND DISCUSSIONS}

\section{Performance Characteristics}

\section{Brake Thermal Efficiency (BTE)}

The variety of Brake Thermal Efficiency with Brake Power for various mixes of biodiesel as appeared in Figure 1. For all the powers tried the Brake Thermal Efficiency increments with increment in load. This is because of, decrease in heat misfortune and increment in influence with increment in load. The Brake Thermal Efficiency of biodiesel mixes was seen as lower contrasted with diesel at all force yield. This is because of, the lower calorific worth, higher consistency, higher thickness which prompts poor atomization of biodiesel than diesel which results into increment of Brake Thermal Efficiency for diesel than biodiesel mixes. At $80 \%$ burden condition every single tried fuel give higher Brake Thermal Efficiency than at $100 \%$ burden condition. This is because of the way that, the force delivered from the motor is not exactly the measure of fuel devoured to build up that power at $100 \%$ burden condition with the goal that Brake Thermal Efficiency diminishes at $100 \%$ burden condition when contrasted with $80 \%$ burden condition.

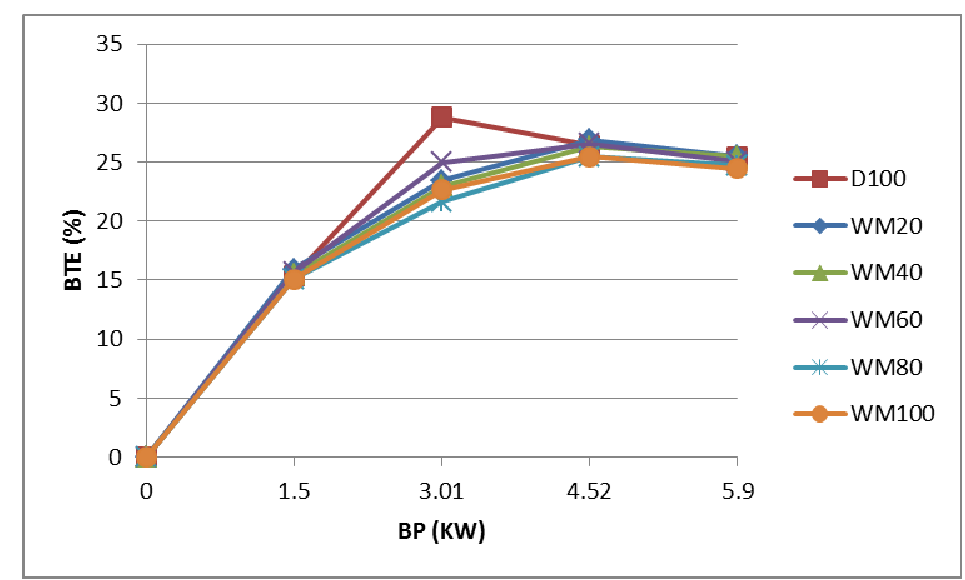

Figure 1: Brake Power Vs Brake Thermal Efficiency.

\section{Brake Specific Fuel Consumption (BSFC)}

The variety of Brake Specific Fuel Consumption with Brake Power for various mixes of biodiesel as appeared in Figure 2. As the heap builds Brake Specific Fuel Consumption diminishes. It is seen that Brake Specific Fuel Consumption for biodiesel mixes is higher when contrasted and diesel. For successful consuming of the fuel the calorific estimation of the fuel ought to be higher so the vanishing of the fuel is additionally high. The calorific estimations of mixes of biodiesel are lower when contrasted and diesel; consequently the fuel dissipation is more slow. More slow vanishing rates prompts higher brake explicit fuel utilization. 

Ignition Engine Fuelled with Various Blends of Water Melon Biodiesel

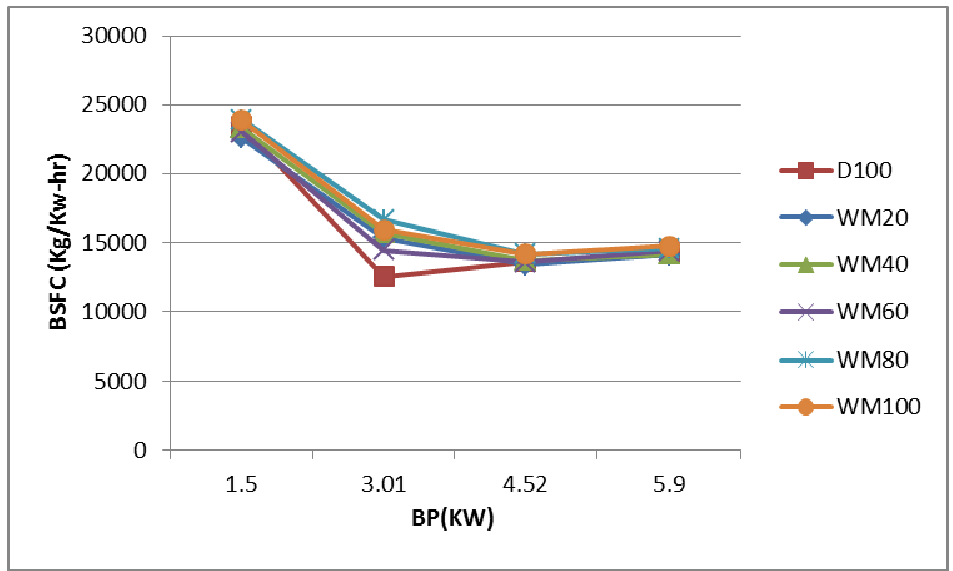

Figure 2: Brake power Vs Brake Specific Fuel Consumption.

\section{Emission characteristics}

\section{Hydrocarbon (HC) Emissions}

The variety of Hydrocarbon outflows with Brake Power for various mixes of biodiesel as appeared in Figure 3. The slick diesel show lower measure of Hydrocarbon outflows when contrasted with biodiesel mixes. This is principally because of, higher consistency of biodiesel mixes which prompts poor blending of fuel and air results into deficient burning.

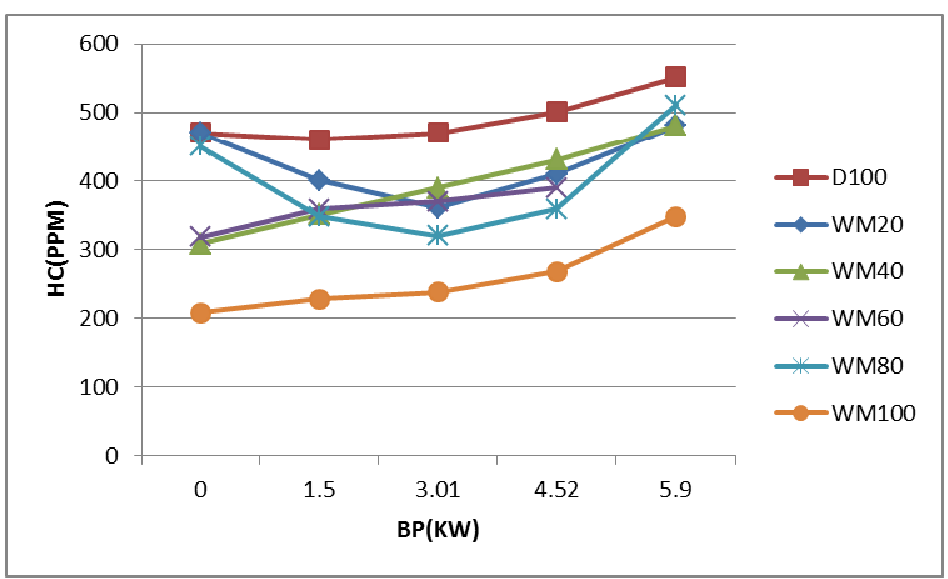

Figure 3: Brake power Vs Hydrocarbon Emission.

\section{Carbon Monoxide (CO) Emissions}

The variety of Carbon Monoxide discharges with Brake Power for various mixes of biodiesel as appeared in Figure 4. The slick diesel show lower measure of Carbon Monoxide emanations when contrasted with biodiesel mixes. This is chiefly because of, higher thickness of biodiesel mixes which prompts poor blending of fuel and air results into fragmented burning. 


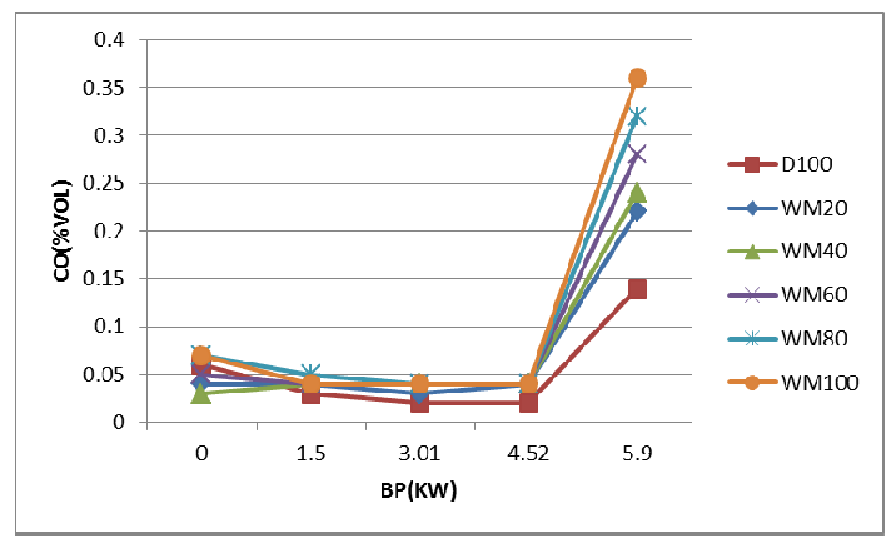

Figure 4: Brake Power Vs Carbon Monoxide.

\section{Nitrogen Oxide (NOx) Emissions}

The variety of Nitrogen Oxide discharges with Brake Power for various mixes of biodiesel as appeared in Figure 5. The slick diesel show higher measure of Nitrogen Oxide outflows when contrasted with biodiesel mixes. This is principally because of, diesel having higher calorific worth and lower thickness than biodiesel mixes. This outcomes into better blending of fuel and air which leads into complete burning of fuel. The total ignition of fuel results higher Peak Pressure Rise rate and higher Exhaust Gas Temperature which prompts higher estimation of Nitrogen Oxide emanations than biodiesel mixes.

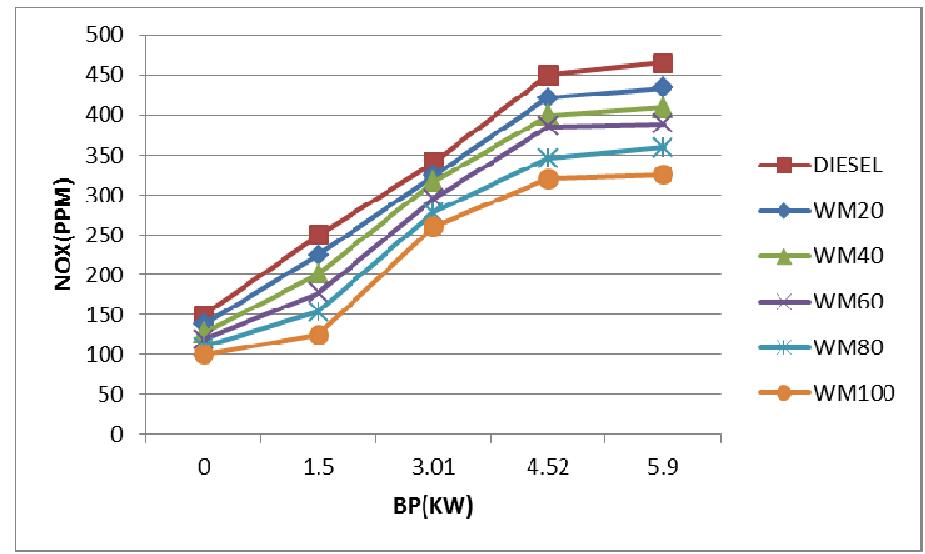

Figure 5: Brake Power Vs Nitrogen Oxide.

\section{Smoke Opacity}

The variety of Smoke Opacity with Brake Power for various mixes of biodiesel as appeared in Figure 6. The perfect diesel show lower measure of Smoke Opacity when contrasted with biodiesel mixes. This is because of, higher consistency of biodiesel mixes the atomization of fuel gets poor and this prompts higher smoke emanations. 


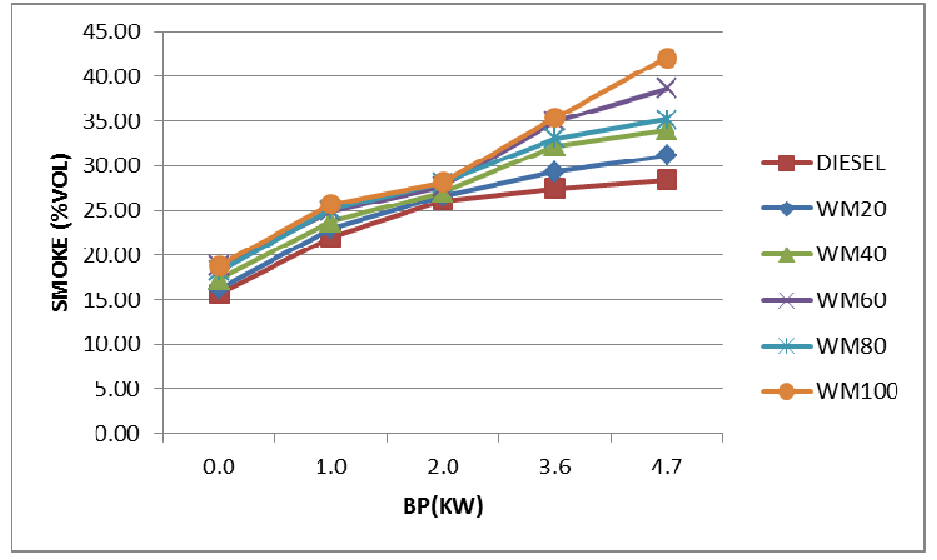

Figure 6: Brake Power VsSmoke.

\section{CONCLUSIONS}

The Brake Thermal Efficiency of biodiesel mixes was seen as lower contrasted with diesel at all force yield. Absolute Fuel Consumption for diesel is less when contrasted with biodiesel mixes. Brake Specific Fuel Consumption for mixes of biodiesel mixes is higher when contrasted and diesel. The slick diesel show lower measure of Hydrocarbon emanations when contrasted with biodiesel mixes. The slick diesel display lower measure of Carbon Monoxide discharges when contrasted with biodiesel mixes. The flawless diesel display higher measure of Nitrogen Oxide emanations when contrasted with biodiesel mixes. The slick diesel show lower measure of Smoke Opacity when contrasted with biodiesel mixes. Among the biodiesel mixes tried, B20 gave the best execution with decreased emanations. The BTE of the motor with the B20 mix at $80 \%$ force yield which is nearer to diesel activity. Subsequently B20 mix is suggested for existing diesel motor.

\section{REFERENCES}

1. S. Saravanan, G. Nagarajan, G. Lakshmi NarayanaRao, S. Sampath.Combustion characteristics of a stationary diesel engine fuelled with a blend of crude rice bran oil methyl ester and diesel. Energy, 2010, 35, 94100.

2. G. Kasiraman, B. Nagalingam, M. Balakrishnan. Performance, emission and combustion improvements in a direct injection diesel engine using cashew nut shell oil as fuel with camphor oil blending. Energy, 2012, 47, 116-124.

3. H. Sharon, K. Karuppasamy, D.R. Soban Kumar, A. Sundaresan. A test on DI diesel engine fueled with methyl esters of used palm oil. Renewable Energy,2012, 47, 160-166.

4. B.S. Chauhan, N. Kumar, H.M. Cho, H.C. Lim. A study on the performance and emission of a diesel engine fueled with Karanja biodiesel and its blends. Energy, 2013, 56, 1-7.

5. G. Paul, A. Datta, B.K. Mandal. An Experimental and Numerical Investigation of the Performance, Combustion and Emission Characteristics of a Diesel Engine fueled with Jatropha Biodiesel. Energy Procedia, 2014, 54, 455-467.

6. S.K. Nayak, B.P. Pattanaik. Experimental Investigation on Performance and Emission Characteristics of a Diesel Engine Fuelled with Mahua Biodiesel Using Additive. Energy Procedia, 2014, 54, 569-579.

7. H.C. Ong, H.H. Masjuki, T.M.I. Mahlia, A.S. Silitonga, W.T. Chong, K.Y. Leong. Optimization of biodiesel production and engine performance from high free fatty acid Calophylluminophyllum oil in CI diesel engine. Energy Conversion and Management, 2014, 81, 30-40.

8. A. Sanjid, H.H. Masjuki, M.A. Kalam, M.J. Abedin, S. M. AshrafurRahman. Experimental Investigation of Mustard Biodiesel 
Blend Properties, Performance, Exhaust Emission and Noise in an UnmodifiedDiesel Engine. APCBEE Procedia, 2014, 10, 149-153.

9. K. Vijayaraj, A.P. Sathiyagnanam. Experimental investigation of a dieselengine with methyl ester of mango seed oil and diesel blends. AlexandriaEngineering Journal, 2016, 55, 215-221.

10. Basavaraj M. Shrigiri, Omprakash D. Hebbal, K. Hemachandra Reddy.Performance, emission and combustion characteristics of a semi-adiabaticdiesel engine using cotton seed and neem kernel oil methyl esters.Alexandria Engineering Journal, 2016, 55, 699-706.

11. K. Bhaskar, G. Nagarajan, S. Sampath. Optimization of FOME (fish oilmethyl esters) blend and EGR (exhaust gas recirculation) for simultaneouscontrol of NOx and particulate matter emissions in diesel engines. Energy,2013, 62, 224-234.

12. C. Ciubota-Rosie, M. Macoveanu, C.M. Fernandez, M.J. Ramos, A. Perez,A. Moreno. Sinapisalba seed as a prospective biodiesel source. Biomassand Bioenergy, 2013, 51, 83-90.

13. A.B. Fadhil, W.S. Abdulahad. Transesterification of mustard (Brassicanigra) seed oil with ethanol: Purification of the crude ethyl ester withactivated carbon produced from de-oiled cake. Energy Conversion andManagement, 2014, 77, 495-503.

14. P. Verma, V.M. Singh. Assessment of diesel engine performance usingcotton seed biodiesel. Integrated Research Advances, 2014, 1(1), 1-4.15. O.A. Ogunwole. Production of biodiesel from watermelon (CitrullusLanatus) seed oil. Leonardo J. Sci., $2015,27,63-74$.

15. Nicholas Chammoun, Daniel P. Geller, K.C. Das. Fuel properties,performance testing and economic feasibility of Raphanussativus (oil seedradish) biodiesel. Industrial Crops and Products,2013, 45, 155-159.

16. A. Sanjid, H.H. Masjuki, M.A. Kalam, S.M. AshrafurRahman, M.J.Abedin, S.M. Palash. Impact of palm, mustard, waste cooking oil andCalophylluminophyllum biofuels on performance and emission of Clengine. Renewable and Sustainable Energy Reviews, 2013, 27, 664-682.

17. D.N. Basavarajappa, N. R. Banapurmath, S.V. Khandal, G. Manavendra.Performance Evaluation of Common Rail Direct Injection (CRDI) EngineFuelled with Uppage Oil Methyl Ester (UOME). Int. J. Renewable EnergyDevelopment, 2015, 4(1), 110.

18. N.R. Banapurmath, P.G. Tewari, R.S. Hosmath. Performance andemission characteristics of a DI compression ignition engine operated onHonge, Jatropha and sesame oil methyl esters. Renewable Energy,2008,33, 1982-1988

19. Ganesan, S., Rajasekar, R., Gogineni, P. Indian Journal of Environmental Protection.11:985-988(2019).

20. Rajasekar, R., Ganesan, S., Kumar, M.S. Indian Journal of Environmental Protection.10:924-927(2019).

21. Rao, K. N., \&Meeravali, S. N. Effect Of Cooled Egr Technique On Performance And Emissions Of Crdi Engine Operated With Biodiesel Blends.

22. Shtain, G. V., \&Panfilov, A. A. Formation Of Driving Torque Of Engine Inthe Technological Transport Machine With Multiphase Injection Of Fuel.

23. Jayaraman, K., \&Kuppusamy, V. Effect Of Injection Pressure On A Diesel Engine Using Pyrolysis Bio-Oil From Spirulina Algae.

24. Pradeepraj, R., \&Rajan, K. An Experimental Investigation On Diesel Engine Performance Using MoringaOlifera Biodiesel With The Effect Of Different Injection Pressures.

25. Latypov, R. A. The Thermodynamic Calculation Of Offset Shafts Rotary Engine Ideal Cycle With External Heat Supply. 